This item was submitted to Loughborough's Research Repository by the author.

Items in Figshare are protected by copyright, with all rights reserved, unless otherwise indicated.

\title{
Graphic design as visual arguments: does this make a reliable appraisal possible?
}

PLEASE CITE THE PUBLISHED VERSION

https://doi.org/10.1007/978-3-030-32415-5_7

PUBLISHER

Springer

VERSION

AM (Accepted Manuscript)

PUBLISHER STATEMENT

The final authenticated version is available online at https://doi.org/10.1007/978-3-030-32415-5_7.

LICENCE

CC BY-NC-ND 4.0

\section{REPOSITORY RECORD}

Van-Der-Waarde, Karel. 2019. "Graphic Design as Visual Arguments: Does This Make a Reliable Appraisal Possible?”. Loughborough University. https://hdl.handle.net/2134/12957290.v1. 


\title{
Graphic design as visual arguments: does this make a reliable appraisal possible?
}

\author{
Karel van der Waarde
}

\begin{abstract}
The article shows how assessments of graphic design can be made more reliable when graphic design is approached as a visual argument. Each designed object makes a claim that it is improving a situation thereby implicitly stating that a current situation was not satisfactory.

This article uses two warning pictograms as examples to show how visual information can be assessed. The pictograms warn against the risks of taking medicines while pregnant, and the potential affect of medicines on driving cars. These pictograms claim that they warn effectively about possible unwanted effects of a medicine. Toulmin's diagram describes the relation between a claim and its supporting evidence and reasons. An application of this diagram to both pictograms shows that just assessing the claim is not sufficient, and that it is necessary to question the available evidence and reasons too. At least six different fields provides rules and principles that can can be used to assess the evidence and reasons. Designers, clients, legislation and standards, professional peers, people/patients, and society can all legitimately assess the design of pictograms.

One of the major challenges for graphic design is to find relevant evidence and reasons, and to consider these in such a way that a balance between the different fields is achieved.
\end{abstract}

\section{Assessing graphic design?}

Due to the practical nature of the profession, it is hard to define exactly what graphic design is. Practicing designers will give very different descriptions of their activities, aims, and results (van der Waarde, 2012). The shelves in a bookshop under the heading of 'graphic design' show a similar variety. It is likely that there are books on corporate identity, posters, pictograms, signage, typography, historical reviews, biographies of designers, webdesign, and books on tattoos, streetsigns, and calligraphy. It is hard to see what these topics have in common and why these are all classified under 'graphic design'. And it is not only the bookshops and practicing designers that define and describe graphic design. Researchers, museum-staff, teachers, publishers, librarians, job centers, and governments all have their own definitions and descriptions, and there can be substantial differences within these groups. 
It is surprising that most of these groups look mainly at the 'designing' of visual information. The emphasis is on the 'making', which are the activities to design and develop visual artefacts. The 'interpretation' of visual information receives much less attention. A description of graphic design that relates both these areas could be: ' graphic designers make information visual in such a way that the connections of a client are enabled to notice, read, learn, consider, and act.'

Any new design claims that it will change an existing situation into a preferred one. Inherently, any new design therefore criticizes the existing situation and makes a claim that the suggested change is an improvement. Making such a claim requires a form of an 'argument' in which the claim is motivated by comparing the existing situation with a changed situation. Both the 'designing' as well as the 'interpreting' can be seen as an argument because both change towards a new situation. In other words 'graphic designers produce visual arguments for their clients'. Visual arguments aim to verifiable change situations for both clients and people by enabling, empowering, and equipping beholders to act (van der Waarde, 2018).

Both sides, the 'development of an argument' and the 'interpretation of an argument', are essential to assess graphic design. The lack of clear boundaries and a clear core of the graphic design profession makes it hard to discuss these assessments in general, and it is therefore necessary to reduce the scope to a manageable topic.

\section{Example: two medical pictograms.}

Pictograms to inform patients about medicines provides a suitable example. A first example warns against the risk of taking medicines while pregnant, and a second example warns against the risk of a negative influence of medicines on driving behaviour. Both pictograms appear on the outside of packaging for medicines that are prescribed by a doctor and dispensed by a pharmacist. These pictograms are mainly used in Spain and France.

There is ample evidence of the negative consequences of the use of medicine during pregnancy. And it is very clear that some medicines do influence driving behaviour because they make patients drowsy and sleepy. However, it is not exactly known how many people are affected in reality. Road accident statistics rarely record 'medicine-use' as a possible cause, and medicine use during pregnancy is usually avoided as much as possible.

\section{Example 1: Pregnancy warning}

In France, since October 17, 2017, two pictograms draw attention to the risks related to the use of medicines during pregnancy. Figure 1 shows a 'warning' in a red triangle, and a 'prohibition' in a red circle with a diagonal slash. Figure 2 shows four alternative pictograms that are used in different types of patient information, but these do not appear on the outside of medicine boxes. 


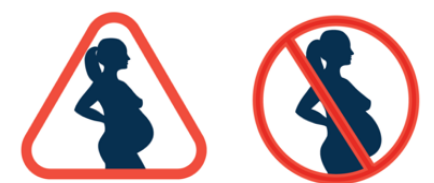

Figure 1: Pictograms that appear on medicine packaging in France. Warning: 'may influence', and prohibition: 'don't take'.

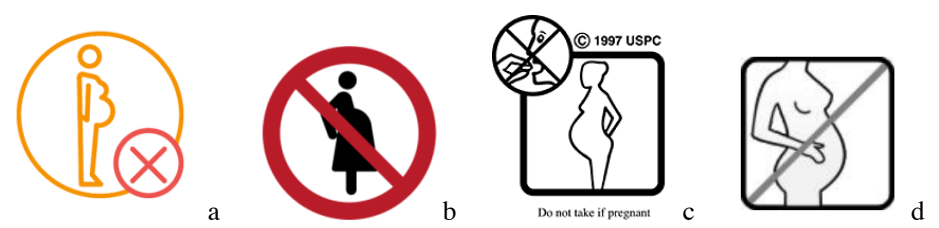

Figure 2: Alternative symbols or pictograms for 'Do not take during pregnancy'. These are not used on medicine packaging.

The pictograms in figures 1 and 2 show a range of approaches to indicate 'a pregnant woman' and 'do not'. A pregnant woman is illustrated in profile because this perspective is most characteristic. This can be visualized as an outline (figure 2a, $2 \mathrm{c}, 2 \mathrm{~d}$ ) or as a solid form (figure 1 and figure $2 \mathrm{~b}$ ). The 'do not' instruction shows even more variety: a diagonal red line (figure 1 , figure $2 b$ ), a diagonal grey line (figure 2d), a red cross in a circle (figure 2a), and a black cross through a face taking a tablet (figure $2 \mathrm{c}$ ). The outer shapes also vary substantially: a red triangle, a red circle, an orange circle, and a black square in a variation of line-thicknesses. Only one pictogram (figure 2c) is supplemented by a text 'Do not take if pregnant'.

\section{Example 2: Driving warning}

A second example is a pictogram that indicates that 'this medicine might impair your driving'. The French health authorities have made the visual information in figure 3 obligatory in 1999 (AFSSAPS, 2005).
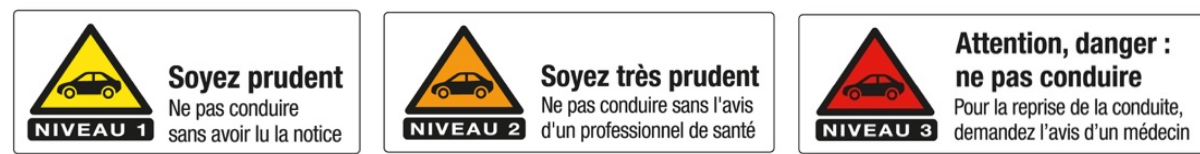

Figure 3: A three-step approach that is obligatory in France.

The colour coding of the pictograms indicates the level of severity. There is a visual inconsistency here too. The triangular shape of the pictogram in figure 3 on niveau 3 implies that these are warnings, indicating that the use of a medicine 'may influence'. This seems to be in conflict with the accompanying text which states it is a prohibition: 'do not drive'. 
The pictogram in figure 4 is legally obligatory since 2011 in Spain (AEMPS, 2012). An experimental study ( $\mathrm{N}=1385)$ showed that " $85.7 \%$, correctly related the symbol with the possible effects of the medicine on driving" (Fierro et al, 2013.p 1059).

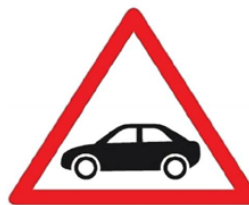

Figure 4: A visual warning on medicine indicating that 'this medicine might impair your driving'.

The Druid project (EMCDDA, 2012) investigated the use of pictograms in warnings for driving. These pictograms have been evaluated in a study with 270 drivers and concluded that 'pictograms can be seen as a valuable means to reinforce both written and spoken information given to patients by health care providers at the time of consultation' (Monteiro et al, 2012). The visual inconsistency of the French pictograms in figure 3 is avoided here by colour coding the 'level of risk', and not by differentiating between 'a warning' and 'prohibition'.

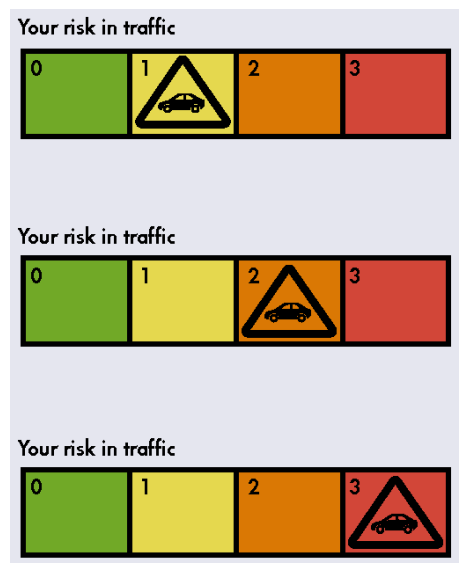

Figure 5: A rating that shows 'your risk in traffic'. This visual was most effective in an experiment $(\mathrm{N}=1006)$ because it provided good insight into the different levels of driving risks. (EMCDDA, 2012. P 30). This is not (yet) used on medicine packaging.

The literature on medical pictograms provides a range of reasons to use pictograms (van Beusekom et al, 2018). The main reasons are that pictograms are faster to interpret than words, that they are language independent, and that they are more visually salient and therefore attract attention. The consistent use of these pictograms since 1999 (Driving) and 2017 (Pregnancy) also seems to suggest that pictograms are an effective way to inform and warn patients. 
These pictograms were designed to change a situation in which patients were insufficiently warned against the risks into a situation in which patients are sufficiently warned. The existence of these pictograms on medicine boxes makes a claim that the addition of pictograms at least amplify the spoken warnings of doctors and pharmacists, and could in optimal circumstances reduce or prevent the risks.

The selection of these two pictograms as examples makes it possible to formulate a question about the assessment of graphic design on a more feasible scale: 'Which evidence is needed to show that these two pictograms effectively warn about possible unwanted effects of a medicine?' Or, in other words, 'could the claim that these pictograms make be correct?'

And this brings us back to the inconclusive definition of graphic design activities and results. If the focus of the assessment is solely on the development of the visual results, the discussion leads to topics like the illustrations, the colours, the shapes, and the line-thicknesses of the pictograms. If the focus expands to include the interpretation and actual effects of these pictograms, a different approach is required.

\section{Do graphic designers really develop visual arguments?}

In order to discuss this claim about the example pictograms, it is necessary to have a look at the kind of evidence that is required. Stephen Toulmin (1922-2009) published in 1958 five essays in 'The Uses of Argument'. The third essay is on 'the layout of arguments' and discusses the relation between 'claims' and 'evidence' (Toulmin, 1958). In this essay, Toulmin related the components of an argument in a diagram (figure 7) where the Claim (C) directly follows from the evidence or Data (D).

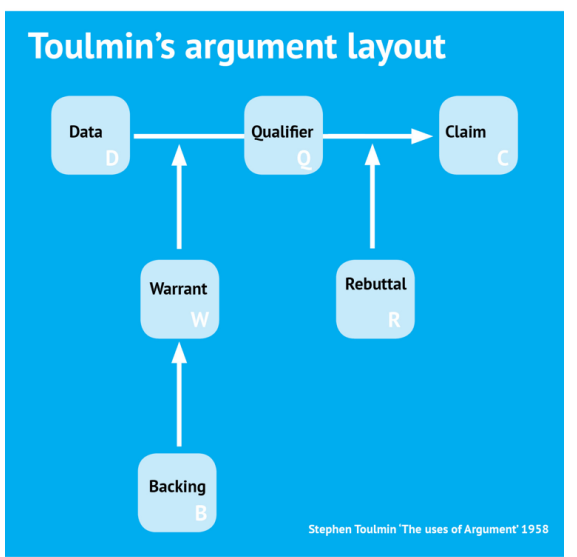

Figure 7: Toulmin's diagram showing the relation between components of an argument. 
Applying the structure of this diagram to both medical pictograms, the argument seems to develop like this:

Claim (C): $\quad$ The claim $\mathrm{C}$ is 'Pictograms are effective to warn pregnant women and car drivers about possible unwanted effects of a medicine.'

In order to make this claim, it is necessary to provide some form of data that supports this claim.

Data (D): Evidence suggests that current warnings are not sufficiently adhered to. This leads to high risk events in traffic and pregnancy, and it is therefore necessary to give additional visual warnings to patients to augment this message.

Qualifier (Q): The claim needs to be qualified to limit the scope because it is unlikely that this claim is applicable in all circumstances and in all contexts. The pictograms only warn for two events, and appear only on medicine packaging in France and Spain.

Warrant (W): A warrant provides a reason why evidence (data) is relevant to the claim by providing 'general rules and principles'. In this example, it is in general important to warn patients about the risks of taking medicines to avoid further harm. And in general, people understand pictograms easier and faster than words. Pictograms are furthermore language independent which makes them easier to interpret for non-native speakers and for people who have difficulties reading texts.

These general principles might be questioned because they are based on a combination of assumptions. Asking why the warrants are selected leads to a - usually implied - authority that can provide a backing.

Backing (B): The rules and principles are backed by an authority. For pictograms, there are several types of backing, as we will see later.

Rebuttal (R): The rebuttal considers the conditions of exceptions in which the claim cannot be correct. Example of rebuttals are: 'Why are these pictograms only used in France and Spain?', 'Are there more effective alternatives to warn patients?' and 'Are we sure that additional warnings are more effective than for example selecting another medicine that does not have these effects?'

The question 'Which evidence is needed to show that these two pictograms effectively warn about possible unwanted effects of a medicine? can now be formulated even more specifically by asking: 'on which rules and principles $(W)$ is this evidence based, and which authorities (B) back this?'

The application of Toulmin's diagram might seem as an unnecessary complication. The question could simply be answered by interviewing designers and their clients, and by observing and interviewing patients who might be at risk, or patients who took the risk. But this straightforward approach would not provide a complete picture of the context in which graphic design needs to be assessed. It would not do 
justice to the complexity of the situations in which both pictograms are designed and interpreted.

\section{Who can assess the quality of visual communication design?}

Until here, the text has mentioned 'designers of pictograms', 'clients' (pharmaceutical industry), and 'patients' (pregnant women and car drivers). It has also mentioned 'French, Spanish, and European legislation'. In addition, there are the views of a professional disciplines, and of a society. Each of these six fields has a specific perspective on the effectivity of both pictograms. Each considers specific evidence to evaluate the claim and assess the graphic design of the pictograms. And, according to Toulmin, each field refers to specific backing authorities (B) that provide a basis for specific rules and principles (W). As Toulmin stated: "The kind of backing we must point to if we are to establish its authority will change greatly as we move from one field of argument to another." (Toulmin, 1958, page 96). This idea of 'field-dependence' in arguments is recently developed further into a more practical approach (Jackson and Schneider, 2018). The six fields below are based on this approach, and start from the idea that the assessment of claims in arguments is based on different fields that are related, but are independent from each other.

\section{Field 1. Design: the visual qualities.}

The visual qualities of two example pictograms vary substantially. The motivations and reasons for design decisions related to the pictures of pregnant women and a car, the colours, the line-thicknesses, and the ways to visualize 'don' $t$ ' remain unknown. However, there must have been a designer who has carefully considered these visual variables, and considered design criteria like aesthetics and originality. Furthermore, the practical use of these pictograms shows that the evidence that the designers provided must have convincing enough for clients to accept and use both pictograms.

Field 2. Client: commercial and strategic qualities.

The pictograms were commissioned by a pharmaceutical industry, governmental institute, and a research organization. They aim to make sure pregnant women will not take particular medicines because it is safer for mother and baby. The driving pictograms might increase road safety. These considerations are based on the idea that both governments and pharmaceutical industry must cooperate in their longer term strategy related to the safety of patients. A more cynical view is that the use of these pictograms mainly aims to reduce the risk of liability claims. The commercial benefits and risks of the use of these pictograms on medicine packaging have been carefully considered.

Field 3: Standards and legislation: the legal qualities. 
The European legislation specifically mentions 'pictograms' in relation to health education. The legislation states: 'The outer packaging and the package leaflet may include symbols or pictograms to clarify certain information ...' (Directive 2001/83/EC, 2001; Article 62). France and Spain have applied this legislation and have added pictograms. Apart from the legislation, there are also standards for the design and evaluation of pictograms by the International Standards Organization (ISO). For example, there is a standard for designing symbols (ISO 22727), and there are three standards for testing symbols (ISO 9186). If the same pictograms are used on a screen, which is highly likely, the accessibility standards of the WorldWideWeb Consortium (W3C) will apply too. Adhering to legislation, and following international standards increases the likelihood that the warnings are effective.

Field 4: Professional discipline: the professional qualities.

The disciplinary considerations look at the acceptability of approaches that are underlying professional practice and its education. Medical disciplines aim to 'do no harm', and use 'evidence based practice' that is disseminated through academic publications, research reports, and protocols. Design disciplines aim to promote good design through 'best practice', design awards, and endorsing the 'best examples' in trade-magazines, annuals, and on websites.

Field 5: Users: usability, applicability, understandability.

The fifth field that could examine the validity of the claim are the users (people, beholders, patients) of these pictograms. Especially pregnant women and car drivers need to be able to recognize the illustration ('what is depicted?'), and correctly interpret its intention ('what does it mean?'). These users decide if these pictograms are noticeable, understandable, and relevant in their personal context. Whether people actually decide to follow or ignore these warnings remains to be investigated.

\section{Field 6: Society: long term benefits and sustainability.}

The sixth field relates to the expectations and requirements of a society. Do pregnant women, which is a relatively small group, and car drivers, which is a substantial group, warrant this additional warning on the tight space of a medicine packaging? How do male patients who do not drive a car react? What is further unknown at the moment is the effect of these pictograms on the costs of healthcare. For example, doctors cannot know what a specific medicine package looks like. And pregnant women can only see the 'pregnancy pictogram' after they have collected their medicines from a pharmacy. This collection can only occur after a consultation with a doctor who prescribed the medicine. If pregnancy was discussed during a consultation, than the pictogram will cause a conflict between the advice of the doctor ('take it'), and the warning on the packaging ('don't' take it'). This could lead to additional consultations, and an increased insecurity about the risks of a medicine. 
Each of these six fields considers different kinds of evidence to assess if 'pictograms are effective to warn pregnant women and car drivers about possible unwanted effects of a medicine'.

\section{Discussion: applying Toulmin's diagram to visual design assessments.}

This discussion brings the three previous sections together. In order to assess graphic design, it was necessary to take three steps:

- choose examples to reduce the scope of the discussion to manageable dimensions (= focus on two pictograms);

- select an approach to assess these two pictograms (= Toulmin's diagram of argument components);

- determine the different fields that are able to provide assessments (= field dependent arguments)

Based on these three steps, it is now possible to determine the 'general rules and principles' in each of these fields, and describe on which authority these rules and principles are based. Toulmin called these 'warrant' and 'backing'.

This suggests that each of the six fields discussed in section 4 needs different types of evidence, and that they use different warrants and backing. Table 1 shows the kinds of evidence that could be provided to support a claim in six different fields.

\begin{tabular}{|c|c|c|c|}
\hline Field & $\begin{array}{l}\text { Backing }(\mathrm{B}) \text { : } \\
\text { Authority }\end{array}$ & $\begin{array}{l}\text { Warrant }(W) \\
\text { General rules and principles }\end{array}$ & Evidence, data (D) \\
\hline 1. Design & $\begin{array}{l}\text { Individual expertise, } \\
\text { design methods and } \\
\text { process }\end{array}$ & $\begin{array}{l}\text { Designers have professional ex- } \\
\text { perience and ability to design } \\
\text { specific visual information. }\end{array}$ & Experience, opinion. \\
\hline 2. Client & Economic structure & Specific commercial interests & Financial monitoring \\
\hline 3. Law/standards & $\begin{array}{l}\text { Legal structure, inter- } \\
\text { nationalization }\end{array}$ & $\begin{array}{l}\text { Specific legislation and stand- } \\
\text { ards }\end{array}$ & Compliance, approval \\
\hline 4. Discipline & $\begin{array}{l}\text { Disciplinary bounda- } \\
\text { ries and activities }\end{array}$ & Promote best practice & Empirical evidence. \\
\hline 5. Users & Human centered. & User centered design & $\begin{array}{l}\text { Benchmarking, monitor- } \\
\text { ing, observations, user in- } \\
\text { terviews, empirical evi- } \\
\text { dence. }\end{array}$ \\
\hline 6. Society & Long term survival & $\begin{array}{l}\text { Sustainability, ecological, so- } \\
\text { cial inclusion. Cultural. }\end{array}$ & Empirical evidence. \\
\hline
\end{tabular}

Table 1: The relations between field, backing, warrant, and evidence. 
According to Toulmin these backing (B) and warrants (W) are essential to validate the relation between data and claim in each field. This means that it is now possible to describe which evidence is required to support the claim 'pictograms are helpful to warn against two specific risks' in each of the six fields.

Assessing design evidence. A pictogram can be seen as successful if the design is based on the expertise of a designer or a design-studio, it seems functional, it is aesthetically correct and original, and fulfills the brief of the client. The general principle (W) is that designers have a professional training and experience to consider a combination of requirements within financial and time-limitations of a client. This is backed (B) by the premise that designers have professional expertise, and apply design methods and design processes to develop an acceptable - but hopefully an extraordinary - visual proposal. The claim gets stronger if the designer increases experience, expert skills, and specialist knowledge.

Assessing financial evidence. A pictogram can be seen as successful if it was delivered on time and within a budget, and it fits into a longer strategy of the client. For both the pregnancy as well as the driving pictogram, the aim - apart from the legal obligation - is to show that the pharmaceutical industry cares and warns patients. The longer term aim is to reduce the number of patients who take risks during pregnancy or while driving. The general principle (W) is commercial because 'not warning' might lead to a reduction in sales if patients claim that a medicine has caused harm. The underlying principle (B) is the economic structure in which pharmaceutical industries produce and sell their products. The claim gets stronger if financial data can be provided that indicates potential costs and profits.

Assessing legal evidence and standards adherence. A pictogram can be seen as successful if it is developed according to the method described in ISO-standards and fulfills the legal requirements. The general principle (W) is that it is simply an obligation to adhere to relevant legislation and that following legislation and standards makes pictograms internationally acceptable. The legal system and international standards provide the backing (B) of these general principles. The claim gets stronger if a pictogram conforms to legislation and standards.

Assessing disciplinary evidence. There are several different disciplines involved in the assessment of pictograms. From the design discipline, a pictogram can be seen as successful if it wins awards, is shown at conferences, is published in trade journals, and if it generates more work. In a medical discipline, a pictogram is successful if it proves to be effective in a treatment which might lead to inclusion in protocols and best practice guidelines. The general principle (W) depends on disciplinary characteristics, but the backing (B) is likely a need to develop a discipline through best practice and education. The disciplinary claim therefore gets stronger if it helps to develop a professional discipline. 
Assessing evidence of successful use. A pictogram can be seen as successful if it enables individual patients to make appropriate decisions and are able to act in the most beneficial manner. There is experimental evidence from two studies that people are able to interpret the 'driving pictogram' correctly, but it is by no means certain that all patients will actually adhere to the warnings. The general principle (W) is that the design must be 'user centered'. The backing (B) is provided by a human-centered approach that focus on the activities and behaviour of people. A claim gets stronger if empirical data about the reactions of different people are available and there is some proof that it is 'not excluding' particular groups.

Assessing societal evidence. A pictogram can be seen as successful if it benefits a society in any way. This can be financial by reducing healthcare costs through the prevention of extra costs, ecological by reducing waste and energy consumption, inclusivity by not excluding particular groups, and so on. A claim gets stronger if it really reduces the number of people who drive a car after taking medicines that affect driving behaviour, and if it really reduces the number of women who take medicines during pregnancy. The general principle $(\mathrm{W})$ are related to the rules that keep a society going, which are based (B) on the need for a long term survival. These criteria can only be monitored over a longer period of time.

The description of the general principles and rules (W) and their backing (B) on which authority these rules are based shows that each of these six fields requires different kinds of evidence to assess a claim. The evidence can come from personal experience, benchmark studies, observations, empirical studies, legal approval, adherence to standards, and user interviews. It is unlikely that different fields accept evidence from other fields without a thorough discussion.

The application of Toulmin's model, and especially a consideration of the warrants and backing, shows that it is necessary to consider evidence in at least six fields to assess if a claim is correct. Focusing on a single field, and accepting the evidence in a single field only, could lead to an incorrect acceptance or rejection of a claim. The evidence that supports the use of the two example pictograms remains scattered and is inconclusive in several fields.

\section{Conclusions}

This article provides an overview of the criteria that can be used to assess examples of visual information. The design of visual information always makes a claim that the newly designed artefact is part of a beneficial change when compared to the existing situation. However, in order to make this claim, it is essential to support this claim by evidence and reasons. This approach is based on Toulmin's diagram of the components of an argument that shows the relation between 'a claim' and 'its supporting evidence'. Two medical pictograms were used as examples to discuss 
how 'a claim' and 'its supporting evidence' are related. The claim is that 'Pictograms are effective to warn pregnant women and car drivers about possible unwanted effects of a medicine.' It turns out that there are at least six independent fields that can assess a claim. Each of these fields require specific forms of evidence and each field is unlikely to accept the evidence of other fields. In order to design visual information, and claim that the result is effective, it is therefore essential to consider and provide at least six different kinds of evidence to suit the expectations and criteria of each of these six fields.

This article is based on the following assumptions, and it is clear that each of these could be challenged:

- Graphic design as an activity can be seen as 'developing a visual argument'. This might not be true for all activities of all graphic designers.

- Both pictograms are examples of graphic design. It is not sure if both example pictograms are designed by professionals, and it could therefore be possible that the wrong examples are selected.

- Evidence based decisions are preferable above decisions based on irrational unsubstantiated fear-rooted gut-feelings.

However, it is likely that these three assumptions are correct for at least a substantial part of graphic design practice. The main benefit of this approach is that it shows the necessity to provide reasons, evidence, and data to support claims in at least six fields. The application of Toulmin's model reveals different backing authorities on which assessments are based. These are related to fields of design, finances, law, disciplinary practice, user-centered, and society.

This approach has two consequences for graphic designers. It becomes necessary to provide evidence in different fields to support a claim. The difficulty is in finding the balance between the expectations of the different fields, and providing reliable evidence for each of them.

The analysis of visual arguments also shows the complexity of the assessment of two fairly simple pictograms that have clear aims. The actual influence on behaviour of car drivers and pregnant women is unknown, and it is unlikely that any change in behaviour could be directly linked to pictograms on medicine packaging. However, the benefits of these pictograms might be in any of the other fields. Each field could reliably assess the benefits and risks of developing and interpreting pictograms. 


\section{References}

\section{Publications:}

AEMPS (Agencia Espãnola de Medicamentos y Productos Sanitarios). 2012.

Medicamentos y Conducción. https://www.aemps.gob.es/industria/etiquetado/conduccion/pictograma.htm

AFSSAPS (Agence française de sécurité sanitaire des produits de santé). 2005. Informations sur les médicaments et la conduite automobile. https://www.ansm.sante.fr/var/ansm_site/storage/original/application/36fd6bd36152361b7a426456edabffce.pdf

Directive 2001/83/EC. 2001. 'Directive 2001/83/EC of the European Parliament and of the Council of 6 November 2001 on the Community code relating to medicinal products for human use'. Official Journal of the European Communities. L 311/67.

EMCDDA (European Monitoring Centre for Drugs and Drug Addiction). 2012. Driving under the influence of drugs, alcohol and medicines in Europe - Findings from the DRUID project. Luxembourg: Publications Office of the European Union. doi: 10.2810/74023

Fierro, Inmaculada., Gómez-Talegón, Trinidad., Alvarez, F. Javier. 2013. 'The Spanish pictogram on medicines and driving: The population's comprehension of and attitudes towards its use on medication packaging.' Accident Analysis \& Prevention. Volume 50, pp 1056-1061. http://dx.doi.org/10.1016/j.aap.2012.08.009

ISO 9186 (International Standard Organisation). 2014. 'Graphical symbols'. Geneva: ISO.

ISO 22727. (International Standard Organisation). 2007. Graphical symbols - Creation and design of public information symbols - Requirements. Geneva: ISO.

Jackson, S., Schneider, J. (2017). Cochrane Review as a 'Warranting Device' for Reasoning About Health. Argumentation 32. Pp 241- 272. https://doi.org/10.1007/s10503-017-9440-Z

Monteiro, S. P., van Dijk, L., Verstraete, A. G., Alvarez, F. J., Heissing, M., \& de Gier, J. J. 2012. Predictors for patient knowledge and reported behaviour regarding driving under the influence of medicines: a multi-country survey. BMC Public Health, 12, [59]. https://doi.org/10.1186/1471-2458-12-59

Toulmin, Stephen E. 1956 [2003]. The Uses of Argument. Cambridge: Cambridge University Press.

van Beusekom, Mara M., Kerkhoven, Anne H., Bos, Mark J.W., Guchelaar, HenkJan., van den Broek, Jos M. 2018. The extent and effects of patient involvement in pictogram design for written drug information: a short systematic review. Drug Discov Today. 23 (6), pp 1312-1318. https://doi.org/10.1016/j.drudis.2018.05.013

van der Waarde, Karel. 2012. 'Communication Design Education: could nine reflections be sufficient?' in Sharon Poggenpohl (editor): Special issue of Visible language on 'Envisioning a future of Design education'. 46(1/2). pp 8 - 35. 
van der Waarde, Karel. 2018. 'Research and Design Watch: A personal view.' Information Design Journal. 24(1). pp 80 - 84.

W3C. 2008. Web Content Accessibility Guidelines (WCAG) 2.0.

https://www.w3.org/

\section{Pictogram sources:}

Figure 1. https://servier.com/en/new-pictograms-for-drugs-that-may-present-arisk-during-pregnancy/

Figure 2a. https://www.apotheek.nl/kunt-u-dat-even-uitleggen/beelden

Figure 2b. https://www.iso.org/obp/ui\#iso:grs:7010:P042

Figure 2c. https://www.usp.org/health-quality-safety/usp-pictograms

Figure 2d. http://www.bijsluiterinbeeld.nl/ 